\title{
International entrepreneurial strategies in Asia: Taiwanese digital content companies in China
}

\author{
Vicki Chihsuan Chiu \\ Department of Radio and TV, Ming Chuan University, Taiwan, R.O.C. \\ E-mail: chchiu223@gmail.com, chchiu223@hotmail.com. \\ Accepted 7 July, 2011
}

\begin{abstract}
This paper investigated Taiwan-based digital content companies' operation in China and examined their international entrepreneurial strategies. Based on the classification of Schuler and Jackson's (1987) business strategies and the theory of the 'life cycle model', this study selected two Taiwan-based digital content companies (Wang Film and Somode) that represented off-line and web-based firms to look at different evolution of these two types of firms. The research found that off-line digital content firms tended to adopt cost-reduction strategies in their initial stages and innovation strategies in subsequent stages. By contrast, web-based digital content companies mainly adopted innovation and qualityenhancement strategies rather than cost-reduction strategies.
\end{abstract}

Key words: Digital content, entrepreneurial strategies.

\section{INTRODUCTION}

China's accession to the World Trade Organization (WTO) has greatly enhanced global interest in investment in the Chinese media market. Most noteworthy is the rapid growth in demand for digital media. The East Asian region is positioned as a growth area in many forms of digital content and digital service industries. For this reason, China is attempting to catch up and take its place as a production centre to offset challenges from neighbouring countries. Mean-while, Taiwan is seeking to use China both as an export market, and as a production site for digital content industries.

Zahra and George (2002) have defined international entrepreneurship as the process of creatively discovering and exploiting opportunities that lie outside a firm's domestic markets in the pursuit of competitive advantage'. According to this definition, international entrepreneurship is an organization-wide phenomenon, a dynamic process rather than a static action, an important part of a firm's culture, a process involving both exploration and exploittation in international markets, and a set of actions with the intention of helping firms create value for its stakeholders, especially the shareholders (Dimitratos and Plakoyiannaki, 2003).

Studies suggest that entrepreneurs of Chinese background have advantages over those from non-Chinese cultural backgrounds, as cultural and political factors are likely to play a more important role in China than in other national markets. When selecting optimal strategies for entering this politics-oriented country, intending players (producers, distributors, etc.) are aware that China will not be able to meet many international benchmarks on investment environment, regulatory structure and policy implementation. In the immediate future, politics will continue to impact upon investment in content and online industry businesses. Investment in the Chinese market therefore involves many external environmental risks (political, economic and cultural environments). It is within this cultural-political context that Taiwanese-Chinese entrepreneurship and knowledge of business processes may provide distinct advantages.

It has also been suggested that in the international corporate race for the Chinese market, Taiwanese digital content industries need to give full play to operational capabilities, to continually strengthen core competences, and maintain a competition edge in response to various market developments (Ministry of Economic Affairs Digital Content Industry Office, 2004). In view of rapid technological advancement and shortened international product life cycles, the role of entrepreneurship becomes more important. This focus on entrepreneurship was established by the work of Joseph Schumpeter, who argued that 'capitalism is incessantly being revolutionized from within by new enterprise' (McKnight et al., 2001: 6).

The role of the entrepreneur is therefore important to 
be considered in industries such as digital content, where players are entering and operating at various stages of the value chain (McKnight et al., 2001: 14).

Early international entrepreneurship research mostly described new ventures that entered international markets at an early stage, even in their founding period. This study also describes the activities of established Taiwanbased digital content companies. However, there are several reasons for choosing Taiwanese digital content companies:

1) Taiwan and China are culturally proximate and this allows for the transfer of culturally compatible business practices and symbolic content (Straubhaar, 1991). This proximity factor in the past has assisted popular culture industries, such as Taiwanese TV and music. It is assumed that cultural proximity can also apply to digital content.

2) Taiwanese digital content industries have been involved in all segments of the digital content chain in China for many years.

3) Entrepreneurship is highly developed in Taiwan, especially in small and medium enterprises, where $97.72 \%$ of Taiwan's businesses were SMEs in 2002 (Small and Medium Enterprise Administration, 2006). Reports suggest that small and medium-sized Taiwanese investors have more success in China than investors from other countries (Rexrodt, 1994; Linn, 1996; Wang and Ralston, 2000).

\section{International entrepreneurial strategies}

Strategy is a term that can be traced back to ancient Greece, where it was used in military conflicts. Now, it is a popular term used in business. Strategy is generally divided into three kinds: overall strategy, business strategy and functional strategy. The overall strategies are usually formulated by head offices, such as deciding which kind of industry to enter and future development of the company. Business strategies are devised by strategic business unit (SBU) and they entail competitive strategies. Functional strategies include marketing, financial affairs, production and human resources. Therefore, strategic entrepreneurship incorporates entrepreneurial (that is, opportunity-seeking actions) and strategic (that is, advantage-seeking actions) per-spectives to design and implement strategies that create wealth (Hitt et al., 2002: 2). The entrepreneurial process is shown in Figure 1 (Hisrich et al., 2005: 38).

A strategy is an integrated and coordinated set of commitments and actions designed to exploit core competencies and gain a competitive advantage. Business strategies are concerned with a firm's industry position relative to competitors (Porter, 1985, in Galbraith and Schendel, 1983). Many scholars have articulated different classifications of business strategies (Wissema et al.,
1980; Porter, 1980; Miles, 1982; Galbraith and Schendel, 1983; Schuler and Jackson, 1987; Draman et al., 2002, in Galbraith and Schendel, 1983). Porter proposed his wellknown classifications, namely, cost leadership, differentiation and focus in 1980.

Due to the features of digital content industries described further, this study has adopted Schuler and Jackson's classification (1987) that used labels slightly different from Porter (1985) cited in Galbraith and Schendel (1983), namely cost-reduction, innovation and quality-enhancement. According to Schuler and Jackson (1987), cost-reduction strategy involves enhancing competitiveness by lowering the prices of products or services. This method can promote production efficiency and reduce expenditures through the adoption of new technology, enlarging the scale of production, or re-engineering production processes. A firm can sell its products or services at a lower price in the market. Innovation strategy emphasizes the development of products or services that are unique or different from those of the competitors. Finally, the success of quality-enhancement strategy is achieved by offering a standard of quality superior to that of other products or services.

\section{Evolution approach: The life cycle model}

As in much research on entrepreneurship, international entrepreneurship studies have focused on multiple theories, including the resource-based view, transaction cost theory, organizational learning and product life cycle theory (Zahra and George, 2002). Shane (2003: 194) proposes that entrepreneurial strategy is a strategic activity undertaken to discover and exploit opportunities, such as exploiting dynamic capabilities. Based on this dynamic approach, the concept of life cycles to describe the evolution of Taiwanese digital content firms' international strategies in China is employed.

The life cycle model analyses the object (product, firm or industry) that evolves over time, going through different stages of development, achieving different results and market performances (Cassia et al., 2006). Generally, it is divided into four stages by scholars: introduction, growth, maturity and decline (Cassia et al., 2006).

There are two common approaches within theories based on the life cycle model. First, life cycle phases are consequential. Products, firms and industries change over a predictable pattern of development. Secondly, life cycle models are multidimensional. Most studies take into consideration concurrent determinants that cause the shift from one phase to another (Cassia et al., 2006: 15). This study also adopts the second approach.

In integrating the concept of life cycles with entrepreneurial strategies, we can also identify the same four stages. To sum up, entrepreneurs need to engage in activities to adapt to changing market circumstances. 


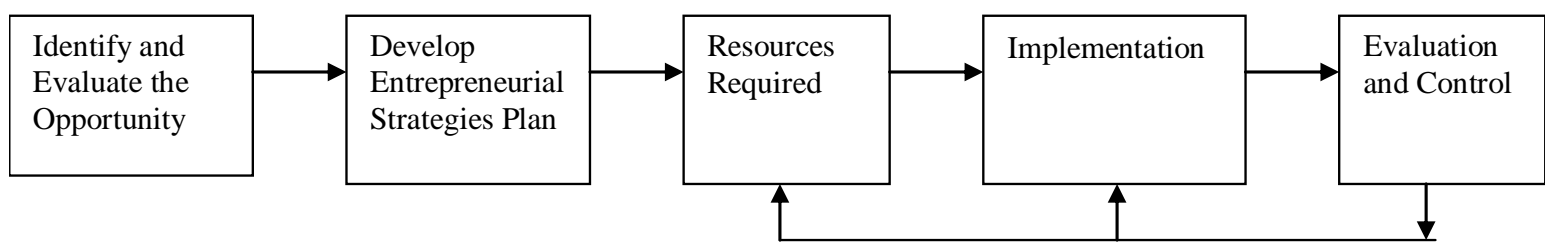

Figure 1. Aspects of the entrepreneurial process (source: compiled by the researcher for this study).

They also need to continually seek opportunities and explore existing resources. There are opportunities to test the validity of the life-cycle theory in the volatile Chinese market and to describe the evolution of the strategies of Taiwanese digital content firms in the Chinese market.

\section{Research questions}

Based on the aforementioned literature review, two research questions were arrived at:

RQ1: How do Taiwanese digital content companies devise their international entrepreneurial strategies in China?

RQ2: How do Taiwanese digital content companies evolve their international entrepreneurial strategies with the pattern of life cycle model in China?

\section{METHODS}

Two Taiwanese digital content firms were selected as case study: Wang Film and Somode. The first, Wang Film, has taken advantage of low cost production, while the second, Somode has been successful in market penetration in China. Another reason for choosing these two firms in this study is that they are examples of companies that present two types of digital content companies in China: off-line - in the sense that their products are produced in more traditional formats, which usually distribute their digital content products via the third party, for instance animation and artworks; web-based whose operations are predominantly web-based, which customers can purchase digital content products online directly, such as digital publication, online game and other kinds of websites.

This study comprises three parts in data collection, including documentation, archival reports and interviews. Field trip was from November 2006 to March 2007; approximately one month was spent in Shanghai, and the rest of the time was spent in Taiwan. The author interviewed the presidents in each company (George Chang, the Suzhou president of Wang Film: 2007 interview: 12 January; and Cheng Yiwei, president of Somode: 2007 interview: 23 February) to acquire insight into entrepreneurship, in particular, entrepreneurial strategies utilized in China. In addition, he also interviewed 12 experts and scholars of $\mathrm{DCl}$ to obtain more neutral opinions to compare with the 'insider view'. Table 1 shows the background of these cases. The numbers of employees for these cases in China are more enormous than Taiwan, and they entered the Chinese market over 10 years.

\section{The evolution of Wang Film (Hong Guang)}

Wang Film, a well-known computer animation company, was established in 1978; its Cuckoos NEST Studio produces more than 250 animation films every year. Due to the time consuming and labourintensive nature of the animation industry, Wang Film from building outsourced production centre in Suzhou China in 1996 enhanced its competitive advantage towards co-production and original content.

\section{Strategy 1: Human resource management}

In its early years, Wang Film had opportunities to produce animation for eight major film studios in Europe and Hollywood. Based on such experiences, other major international media companies, including Walt Disney TV Animation, Metro Goldwyn Mayer, Universal Studios, Rankin Bass Productions, BLT, Bakshi Animation, Film Roman, DIC (France), Nelvana (Canada), CINAR (Canada) and BRB (Spain) established long-term partnerships with Wang Film. Although, digital content is arguably an industry where costs are diminishing (as compared to analogue media), some industry sectors rely on time consuming production processes. The cost of labour initially forced production from US studios to Taiwan. In more recent times, the production has moved to China. Suzhou Wang Film was established in 1996, an independent subsidiary which is comparatively successful, but there are technical transfers from Taipei Wang Film. This circumstance led to the first strategy Wang Film adopted in Suzhou, which is related to human resource management.

Wu Chengneng, the former president of Suzhou Wang Film set up a relationship with Huqiu Technical Art School in training programs. Initially, Suzhou Wang Film selects qualified students from Huqiu Technical Art School and provides one-year training courses during the fourth grade period. After their graduation, these students will acquire another half-year of training in Suzhou Wang Film. This period is similar to the apprentice period of studying handicraft. After that, many students will formally join Suzhou Wang Film's staff. George Chang believes Suzhou Wang Film has a strong reputation in China, and for this reason, many students have a strong desire to participate in the selection. Through this mechanism, Suzhou Wang Film has trained over 10,000 professionals for the Chinese animation industry.

In addition, Suzhou Wang Film also provides higher wages, better welfare and free work environment to attract employees. For example, Taiwanese DC firms mostly adopt the annual performance system in Taiwan. However, Suzhou Wang Film noticed that the Chinese standard salary was lower than Taiwan. Suzhou Wang Film has subsequently adopted a monthly performance system as well as auxiliary annual bonus systems in China. The monthly performance system is a quantitative evaluation system employing average monthly output as a benchmark criterion. If a staff member produces more than usual monthly output, he or she obtains financial awards that month. On the other hand, if the client complaint happens or the cost of specific films is relatively high, Suzhou Wang Film will use auditors to isolate the problem.

\section{Strategy 2: Animation satellite factories}

Following the global depression in late 1990s, customer budgets 
Table 1. The background of two cases.

\begin{tabular}{|c|c|c|c|c|c|c|}
\hline $\begin{array}{l}\text { Companies / } \\
\text { institutes }\end{array}$ & $\begin{array}{l}\text { Core industry } \\
\text { of } \mathrm{DCl}\end{array}$ & $\begin{array}{l}\text { Numbers of total } \\
\text { employee }\end{array}$ & $\begin{array}{l}\text { Numbers of } \\
\text { employee in China }\end{array}$ & $\begin{array}{l}\text { Numbers of } \\
\text { employee in Taiwan }\end{array}$ & $\begin{array}{l}\text { Year of enter } \\
\text { China market }\end{array}$ & $\begin{array}{c}\text { Net profit } \\
\text { (China/whole } \\
\text { company \%) }\end{array}$ \\
\hline $\begin{array}{l}\text { Wang Film / } \\
\text { Cuckoos Nest }\end{array}$ & $\begin{array}{l}\text { Computer } \\
\text { animation }\end{array}$ & Approximately 1000 & 200 to 400 & Approximately 300 & 1996 & $>40$ \\
\hline Somode & $\begin{array}{l}\text { E-publishing } \\
\text { and digital } \\
\text { archiving }\end{array}$ & 70 & 70 & 0 & 2000 & 100 \\
\hline
\end{tabular}

Source: The researcher compiled for this study (2007).

decreased and the gross profit of Taiwanese animation firms diminished. In order to build a more efficient and cost-effective entrepreneurial environment, Suzhou Wang Film set up a flexible employee system called 'animation satellite factories'.

According to Chang (2007), Suzhou Wang Film owns five to six animation satellite factories (or animation studios) at present. Some animation satellite factories also outsourced production to other people. This situation is similar to the household subcontracting system in the 1970s in Taiwan. The number of employees in these satellite factories is high at present. This situation increases the flexibility of human resource management and reduces uncertainty from the orders of foreign firms. For the fact that employees of animation satellite factories are part-time workers, Wang Film can reduce the expenses of employee welfare.

To choose and manage these animation satellite factories, the factories are mainly conscientious about the animation director who is responsible for animation technology. The animation director is also in charge of quality controls; if some animation satellite factories fall short of the specifications, Suzhou Wang Film will let them do the poor work done, over again. If the animation satellite factories cannot finish these works before the deadline, they will suffer the financial punishment such as deduction of payment. In addition, the animation director will collect the feedbacks from each department on animation satellite factories' work. These assessments will impact the next orders to each animation satellite factories.

\section{Strategy 3: Partnership with China central television}

Wang Film misunderstood the Chinese TV animation market during the early stage of their market entry. According to George Chang, Wang Film planned to rewrite famous Chinese popular legends, including Outlaws of the Marsh, Ten Brothers, and adopted the Chinese national sport ping-pong as a theme to create a TV animation, Ping-Pong Boy, to enter the Chinese market. However, these ventures failed.

Why did Wang Film fail at that time? The Taiwanese animation industry structure gives some indications. According to both George Chang and James Wang, the Taiwanese TV animation market is too small to accommodate the domestic animation industry. In addition, competition among the numerous cable TV channels means most Taiwanese TV stations can only pay US $\$ 1,500$ per episode, but the cost of one episode animation is over US $\$ 30,000$. The profit margins are non-existent: the sales revenue of TV animation in Taiwan cannot cover the production costs. George Chang described the structural similarity between the Chinese and Taiwanese TV markets: the TV stations cannot pay high-prices to purchase animation. The income could not even cover the animation paper. In this situation, Taiwanese animation films have difficulty in raising capital to produce branded TV animation without government support. However, Chinese central television (CCTV), one of the clients of Suzhou Wang Film, differs from other TV stations in China. Chinese central television (CCTV) is directly administered by the state administration of radio, film and television (SARFT). It is not only a major broadcast television network in China, but also a powerful propaganda media outlet in China. In that case, Wang Film changed its strategy in early 2000s to become one of the prestige firms, which CCTV calls for a bid before an animation production. Although CCTV does not share animation copyright with production firms, Wang Film still receives considerable revenue from CCTV.

CCTV, Suzhou Wang Film and Hongyang ${ }^{1}$ have cooperated in producing a 52-episode TV animation series, Legend of Nezha. CCTV invested over US $\$ 1.5$ million, and spent three years to finish this film, which was broadcasted by CCTV on 1 June 2003. The namesake comic book was launched by people posts and telecommunications publishing house (PTPress) at the same time. As a result, the Legend of Nezha achieved national success: not only earning over US \$12.4 million in advertising income, but also gaining over US \$ 7.4 million in serial book sales revenue. Legend of Nezha also won the $7^{\text {th }}$ Golden Children Award: The Best Animation Serial Film. Following this, CCTV, Suzhou Wang Film and Hongyang co-operated in producing another 52-episode TV animation series in 2007, called The Adventures of Little Carp. CCTV broadcasted The Adventures of Little Carp three episodes per day both in Dafengche and Cartoon City, two of the most popular children's channels during the 2007 summer vacation. The Adventures of Little Carp also won The $3^{\text {rd }}$ China International Golden Monkey Award: Best Animated Series and Best character Design in April 2007.

\section{Strategy 4: Original content export fire ball (hong hai er: jue zhan huo yan shan)}

Conversely, Taipei Wang Film adopts the US animation industry model from movie to TV, perhaps, influenced by its clients and James Wang's experience in the US, and expanded China as its vital export market. Fire Ball was the first Taiwanese 3D animation movie screened in China, Taiwan, Hong Kong, Indonesia and other Asian countries in August 2005. Its script was rewritten from a traditional Chinese myth of adventure and fantasy called Journey to the West. Fire Ball cost over US\$ 5 million and three years to produce. Wang Film invited the acclaimed Taiwanese director,

\footnotetext{
${ }^{1}$ Hongyang is another Taiwanese company in the beginning, but Hongyang sold 51percent share to Jade Dynasty Group Ltd. in 2007. After that, the ownership of Hongyang belonged to a Hong Kong company.
} 
Wang Toon, to be part of the project. Wang Toon has directed a distinguished trilogy of Taiwan history Straw Man (daocao ren), Banana Paradise (xiang jiao tiantang) and Hill of No Return (wu yan di shanqiu), all of which were well accepted critically and commercially. Fire Ball is his first animation feature. Wang Film also invited a noted Taiwanese dramatist, Ji Weiran, to be Fire Ball's scriptwriter, and sought celebrities such as A-Ya, NONO, Masa, Peng Qiaqia, Yang Guimei, and Chen Zhaorong (Jeff Chen) to be dubbed actors.

Beijing Children Art Theater Limited Company, which successfully launched the Maze (mi gong) and Hi, Cute (Hi, ke'ai), was in charge of Fire Ball's distribution in China; this was the first time it had embarked upon movie production and publishing. Fire Ball created a new ticket retail model in China: pre-sell tickets online through 10 box offices and deliver movies' tickets to people's homes (Mu, 2005). Wang Ying, the president of Beijing Children Art Theater Limited Company believes that the idea of 'combining the theatre' ticket promotion method with traditional cinemas was strongly supported by Beijing New Film Association (Beijing Youth Today, 2005). Ticket sales in most box offices achieved immense success, especially in Capital Age Cinemas, New Dongan Cinemas, and East Circle Cinemas, where weekend tickets were sold out in advance.

\section{The evolution of Somode (Mo De)}

The second case study is an example of a professional digital content provider that employs free, high-quality and interactive content to attract million of readers and advertisers. It generates significant profits in the Chinese e-magazine industry. Until recently, e-magazines were regarded as 'marginal media'. The innovation in this case is that an entrepreneur has concentrated on the new format of e-magazines, and has identified an opportunity. The entrepreneur who has made this to occur is Cheng Yiwei from Taiwan, president of Somode. Cheng has combined product innovation and value innovation to create two of the most popular e-magazines in China: Me Beauty and Wo Style.

\section{Strategy 1: Creative format of e-magazine}

During our discussion, Cheng Yiwei provided the historical background to his company. A firm called Fashionow was established in Taiwan in 1997. It then launched a well-known free P2P MP3 platform Kuro on 11 July 2000. Chen Guohua, its chairman who had a vision of a pan-China market, raised US \$ 6 million to enter the Chinese market in 2000. In order to improve Kuro's membership service, Fashionow released the first pan-Chinese interactive digital magazine Cool Music Journal in July 2002. Cool Music Journal was released in July 2002 and is the earliest interactive magazine in China. At that time, Chen also set up the pattern of Chinese emagazine industry with two systems: content providers and platform service providers (Chen, 2006).

The concept of employing flash format to produce an e-magazine was proposed in a meeting at Mount Yangming presided over by Chen Guohua's younger brother, Chen Guoxiong, in July 2002. Kuro, the foremost product of Fashionow, was steady at that time, and Fashionow was eager to create a second stream of innovative products. In this meeting, the head of the design department presented an e-magazine produced with flash technology, combining flash, video, background music and interactive links. In the same meeting, the idea of utilizing the idea of P2P technology to distribute e-magazines to solve the problem of insufficient broadband was proposed.

Liu Suhua, the vice president of Somode believes that the most chal-lenging part of e-magazines is production. Somode's editorial team places heavy emphasis on leveraging internet features in the planning, creating and packaging of their content. According to Liu (2006), the editorial team always discusses how to present content page by page. She believes that the strength of e-magazines is to store the content of e-magazines like print media; while at the same time, it can have multimedia and interactive features. For example, the e-magazine format allows readers of Me Beauty to examine the teaching process, step by step, by clicking computer icons. In addition, the audience of Me Beauty can save make up, dress, fitness and other useful knowledge in a single file.

\section{Strategy 2: Advertising strategies}

The international federation of the phonographic industry (IFPI), Taiwan, filed for Kuro's P2P system, whose illegal sharing MP3 is owned by member rights holders in August 2003. On 9 September 2005, Taipei District Court convicted Kuro of copyright infringement upon first examination, and Fashionow's president received a criminal conviction. In May 2006, Fashionow decided to build a new brand with its e-magazine department, named Somode. Since then, Somode takes the responsibility to bring in significant income for the company.

Cheng (2007) believes that 'content should earn the first barrel of gold of an e-magazine'. He also regards e-magazine as a medium, which should have the same profit model as a traditional magazine by retail and advertising. Somode has tried to charge readers of $\mathrm{Me}$ Beauty and Wo Style 2 RMB per volume, similar to the price of a ring tone download service in August 2005. However, this model failed (Chen, 2006: 22; Ma, 2006: 32). Somode turns to focus on advertising by strengthening the styles and significance of $e-$ magazines.

Somode provides profoundly interactively rich advertisements, including a psychological test, videos and small games to communicate with their clients. Liu Suhwa, in Chen (2006: 21), believes 'Advertisements in multimedia magazines are usually integrated with content closely, and sometimes, readers do not regard them as advertisements'. Another advantage is that Somode can provide advertisers with the download volume of magazine, the average reading minutes of users, the click rate of advertisements, minutes per view, advertisement cost per click and other audience analysis, such as demographic statistics and reading preferences.

In order to reinforce the influence of e-magazine to advertisers, Somode signed a contract with Muzine for further partnerships in advertising, content and distribution in July 2007. Muzine is one of the earliest e-magazines in China, a business unit under Music Radio, China National Radio. In 2005, Me Beauty, Wo Style and Muzine almost dominated the whole e-magazine market (Chen, 2006). According to the contract, Somode became the chief advertising agency and distributor of Muzine in the China market. Meanwhile, Muzine provides content to support Somode (Donews, 2007). Although, some advertisers still query whether e-magazines can be regarded as media, according to administration of press and publication (Copyright Bureau) of Jiangxi Province (2007), the average advertisement income of Me Beauty and Wo Style was over \$US 50,000 per month in 2007.

\section{Strategy 3: Management buyout and venture capital}

In the initial stages, Somode was a wholly owned enterprise, invested by Fashionow. Some senior officers of Fashionow acquired Somode through a process of 'management buyout' in April 2007. In order to expand its businesses, Somode acquired the first round of venture capital (VC) with \$US 5 million fund from Japan and Singapore in July, 2007. Cheng Yiwei strongly resisted the view that the e-magazine market was declining: 'in fact, other investors still contacted Somode after this round of VC, and expressed their 
interest in our magazines'. Somode reached break-even in July 2007. Although, the amount of the profit is not immense, Cheng felt satisfied about the present situation, and expressed confidence in better profits in the future (Sohu, 2007). In August 2007, Somode was named as one of the 100 Red Herring Asia Companies. It is not only the sole e-magazine media in this list, but it was also the first time that a Chinese e-magazine content provider won this honour ${ }^{2}$.

\section{Comparison}

This study found out that there are significant differences in the entrepreneurial strategies' evolutions between two types of digital content firms: off-line and web-based firms as discussed earlier.

The evolution of Suzhou Wang Film's entrepreneurial strategies can be divided into two phases, as shown in Figure 2. The first phase is the cost-reduction phase, in which Wang Film focused on seeking cheap and good quality employees in China from 1997 to 2002. According to Schuler and Jackson (1987), cost-reduction strategy can enhance competitiveness. Wang Film has reduced expenditures by setting up a branch in Suzhou. In addition, Wang Film has adopted two labour-related entrepreneurial strategies (partnership with Huqiu Technical Art School and animation satellite factories system) to process human resource management. The strategy of partnership with Huqiu Technical Art School was first employed in Suzhou; thus, the initial life cycle was located in the introduction stage. Another strategy of animation satellite factories system has been previously adopted in Taiwan; hence, the initial life cycle was located in the growth stage. These two strategies enabled Wang Film to sell its animation services at a lower price, and developed very well; as such, they have reached the maturity stage at present.

In the second phase, Wang Film adopted innovation strategies that focused on clients and market expansion since 2002. In this phase, Wang Film developed partnership with CCTV, where the initial life cycle of the strategy was located in the introduction stage and has reached the maturity stage at present. In addition, Wang Film imported self-production film, Fire Ball, from Taiwan into China in 2005, whose release completed the life circle of the strategy in a couple of months.

The evolution of Somode's strategies can be divided into two phases, as shown in Figure 3. Somode employed the innovation and quality-enhancement strategies that Schuler and Jackson (1987) proposed in the first phase. It was not only processing the product innovation (new format of e-magazine), but also marketing innovation (advertisements). In addition, Somode employed the concept of quality-enhancement between these two strategies.

In this phase, Somode created the new format of e-magazines in 2003, which converges interactive materials, including voice, music, video and games to enrich every topic. Audience participation has become a real thing, not just a 'slogan'. The audience can read, listen or play Somode's e-magazines totally, on demand. The initial life cycle of this strategy was located in the growth stage, because it was processed and technically transferred from Taiwan by Somode. Another strategy also adopted in this phase was to enrich the advertisements and redefine the e-magazines as media since 2005. As mentioned earlier, the strategy of advertisement came out under the pressure of company's survival; thus, its initial life cycle was located in the introduction stage.

\footnotetext{
${ }^{2}$ Red Herring covers technology, innovation, financial strategies, and capital venture. Its list is an important part of a tradition of identifying new and innovative technology companies and entrepreneurs worldwide. Excellent global Internet firms such as Google, eBay, Alibaba and Allyes ADNetwork have all won the Red Herring 100 Award (DoNews 2007).
}

The second phase of Somode's strategies since 2007 saw the company restructuring via a management buyout and venture capital investments. In China, capital is one of the major challenges for new ventures. Chinese commercial banks have more regulations than other countries. According to Chinese Financial Yearbook (1989 to 1999), cited in Cooper and Yin (2006), only $0.03 \%$ loans were granted to private companies by state-owned banks in 1998. According to Cheng, $30 \%$ of this round of venture capital was planned to enlarge staff and creative new products, 50 to $60 \%$ was aimed to merge other firms, and 10 to $20 \%$ was to enhance technical skills. Therefore, this organization-restructure can also be considered as one of the innovation and qualityenhancement strategies. Due to the fact that Somode plans to introduce a second round of venture capital in the future, the life cycle of this strategy was located in the introduction stage at the beginning, but is located at a grown stage presently.

\section{Taiwan-China hybrid entrepreneurial model}

Recent studies have demonstrated that the nature of ethnic Chinese investment in China has increased dramatically in the past decade. Taiwan is the $4^{\text {th }}$ largest investor in China, following Hong Kong SAR, America and Japan. According to ROC Ministry of Economic Affairs Investment Office (2005), the total contracted value of Taiwanese investment in China reached US\$ 80,089 billion; whereas the total actual utilized value reached US $\$ 39,865$ billion from 1979 to 2004. However, Taiwanese firms numbered 64,188 in China during this period. In addition, a high-proportion of Taiwanese firms invested in China via Hong Kong SAR and Singapore; thus, the actual investment was higher than these figures.

China is a resource rich country; as such, most off-line digital content firms were established in China for resource acquisition, including labour and culturally symbolic materials. The evolution pattern of off-line digital content firms is very similar with other Taiwanese industrial products, such as those Taiwanese electronics clusters in various towns of Dongguan in South China, which are suppliers of raw materials and components for foreign clients. These off-line digital content companies probably searched out other market chances outside China, and tried to maximize the profits through the obtained or integrated resources in China.

This study interprets the chief reasons to fire up the transition of entrepreneurial strategies among off-line digital content firms in China. The foundation condition of entrepreneurial strategies' transformation from cost-reduction to innovation is that the firm has passed the 'mess period' and settled down in China. They may have a better understanding for Chinese market (for example, the structure of Chinese TV animation market) or an improved position to expand market or explore other sources of income. Another more efficient factor is that off-line firms established the official guanxi to foster the secure opportunities to enter local market, such as Wang Film cooperated with CCTV. In this kind of Taiwan-China hybrid, entrepreneurial model is from outsourcing to innovation.

Web-based digital content products much better reflect these characteristics of digital content products that Quah (2003: 298 to 303) proposed: non-rival, infinitely expansible, discrete, spatial and recombinant. A digital good is non-rival when its use by one person will not lower the utility that another person derives from its use. A digital good is infinitely expansible when it can be produced in unlimited numbers, at high speed, and at little or no cost. Infinite expansibility generates non-rivalry. The ability to make limitless number of copies of a digital good means that everyone can have his or her own copy just like an exact original. Digital goods exhibit indivisibility as consumers or producers always use a whole copy of a digital good. The fourth feature, spatiality, means digital goods are both nowhere and everywhere at the same time. They can transmit immediately from one side to the other side of the globe. 


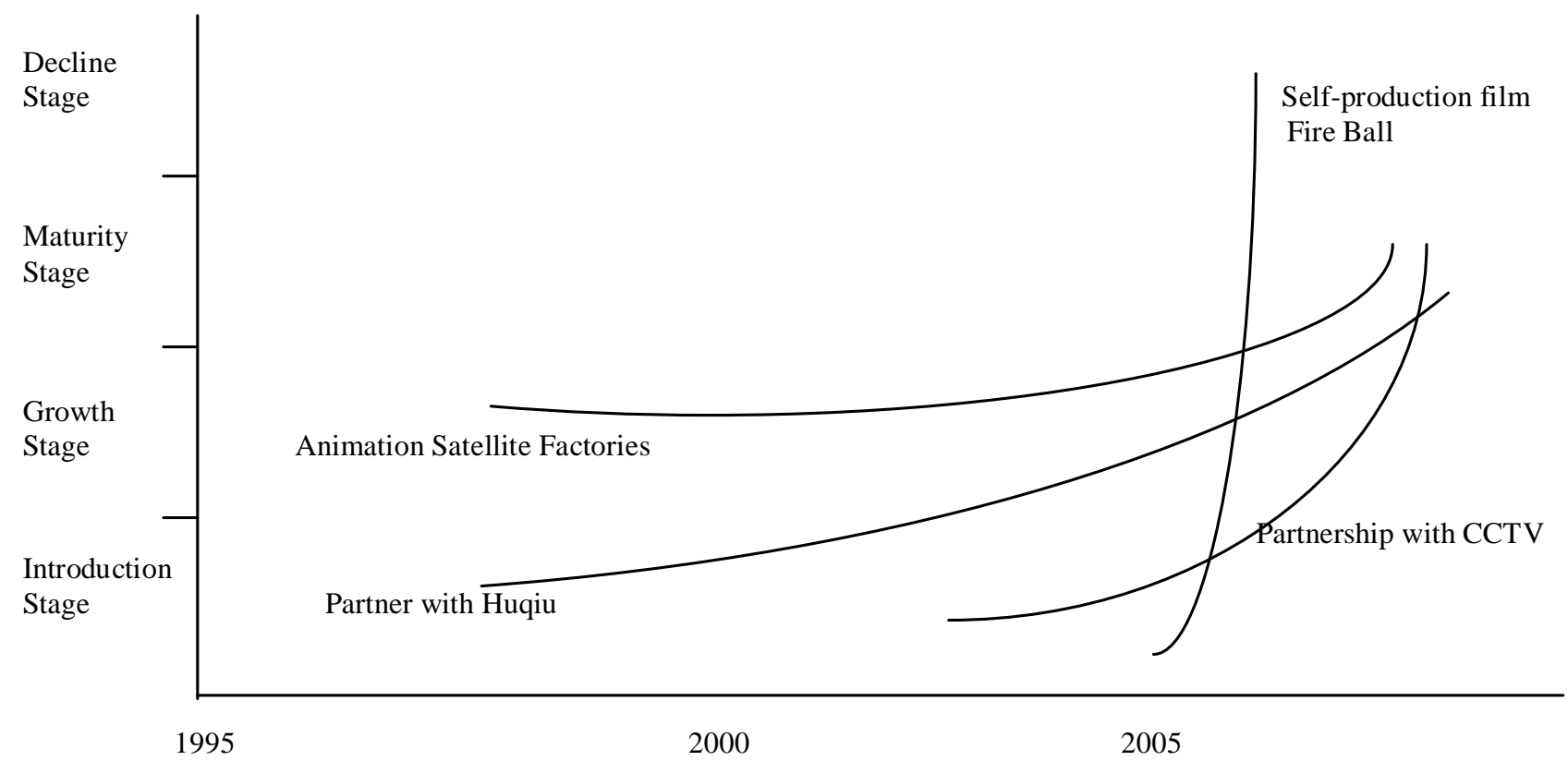

Figure 2. The evolution of Wang Film's entrepreneurial strategies (source: Researcher compiled for this study).

According to Tapscott (1997: 8 to 13), the new economy is a global economy. The fifth property, recombinant, means that new digital goods have characteristics that are not found in the original digital goods. In the new economy, the gap between consumers and producers blurs (Tapscott 1997: 8 to 13).

Due to the low cost of initial production, web-based products are relatively easy to launch than other physical products. However, it is difficult for web-based products to really earn significant profit competitively with billion online products, which customers easily access. The web-based products spent very low cost for distribution and even production; however, they need very high quality output of research and development $(R$ and $D)$, and more marketing expense. In that case, different from off-line digital content firms, web-based digital content companies focus on attracting more audiences and advertisers instead of cost-reduction. They employed innovation and quality-enhancement strategies in whole. The key factors to inspire the entrepreneurial strategies are mostly self-innovation and partnership. Taiwan-China hybrid entrepreneurial model, among web-based digital content companies, is based on the prior experience in Taiwan, and it localizes products and marketing in China.

To sum up, the comparison of the evolution of entrepreneurial strategies between off-line and web-based firms is shown in Table 2.

\section{DISCUSSION}

Other functional entrepreneurial strategies such as: 'product', 'marketing', 'resource acquisition', and 'organizational restructuring', are discussed.

Product strategies include market innovation (Wang Film), concept innovation (Somode) and technological innovation (Somode). The 'core' digital content products and services are computer animation (Wang Film), epublishing and digital archiving (Somode). Most digital content companies produce 'non-core ancillary' products and services. In the cases investigated, they include publications and literature (Wang Film and Somode), motion pictures and videos (Wang Film and Somode), radio and television (Wang Film), software and databases (Wang Film), and advertising services (Somode).

'Related' products and services expand the range from media-based into pan-art and cultural goods, such as various topic tours and branded services. The two digital content firms also produce 'sub-associated' digital content products, including new online products (Somode), new embodied products (Wang Film), traditional products (Wang Film and Somode), and creative industries support products and services (Somode).

The three levels of digital content products in this model do not exclude each other, and sometimes, the boundaries are not clear. Actually, the different levels obtain support from each other, thereby leading to better results. Superior content is always the base of horizontal integration of products and services in digital content industries. This model not only divides digital content products into core, non-core ancillary and related, but also describes the relationships and synergies between digital content industries, content industries and creative industries. In addition, it is also a good model to inspire digital content industries with unlimited possibilities. Digital content industries seem to be ICT-based; however, they can employ creativity from traditional industries. Digital technology is the best medium between old and new media and eventually, digital technology will produce more convergence in these industries.

The marketing strategies of digital content industries in 


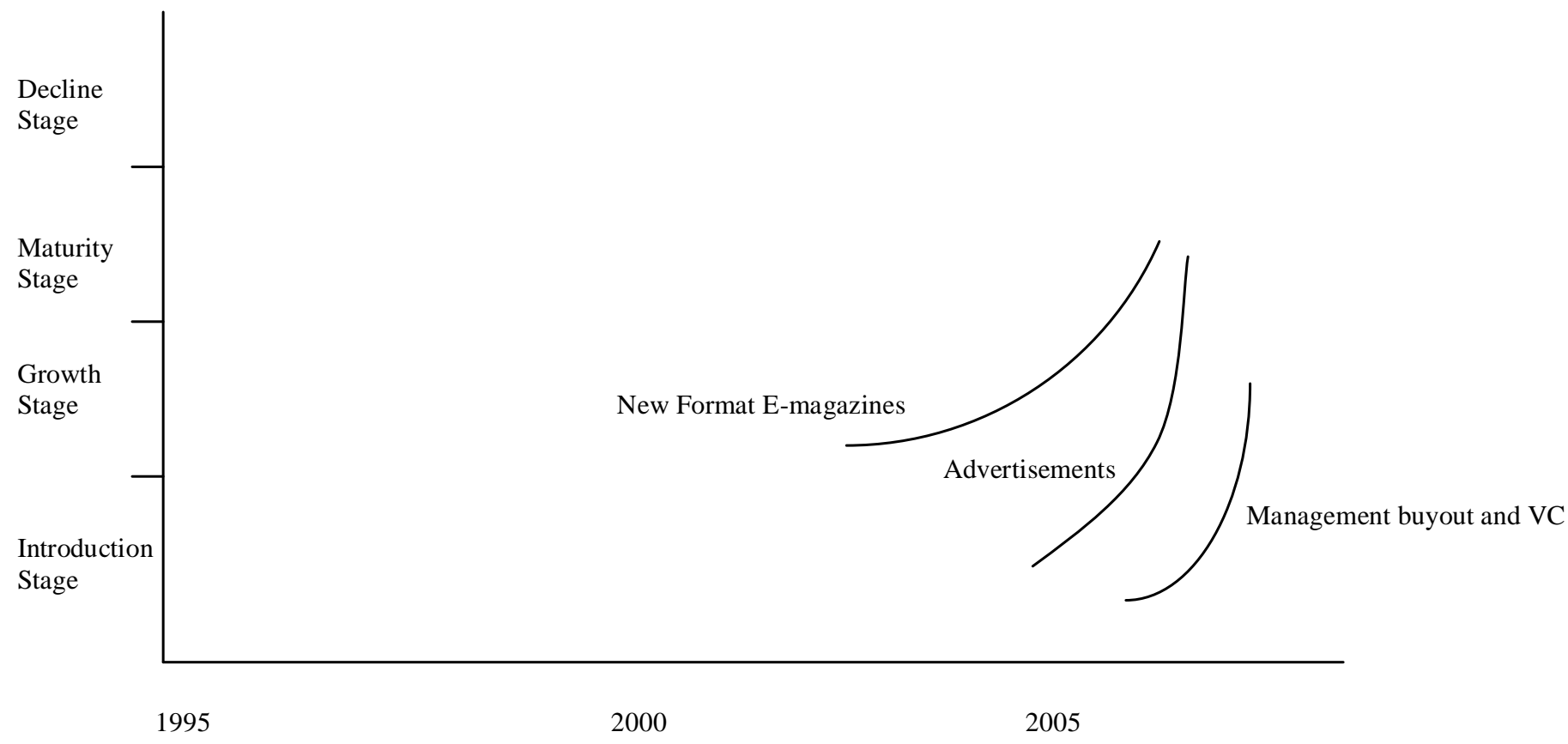

Figure 3. The evolution of Somode's entrepreneurial strategies (source: Researcher compiled for this study).

Table 2. The comparison of the evolution of entrepreneurial strategies.

\begin{tabular}{lll}
\hline & Off-line digital content companies: Wang Film & Web-based digital content companies: Somode \\
\hline & $\begin{array}{l}\text { Partner with Huqiu Animation Satellite Factories } \\
\text { Reasons of the transition: } \\
\text { Expand markets and explore other sources of } \\
\text { income }\end{array}$ & - \\
& Partner with CCTV & \\
& Self-production film 'Fire Ball' & New format of e-magazines \\
Innovation & & Advertising \\
& & Venture capital \\
& - & New format e-magazines \\
Quality-enhancement & Advertising \\
& & Venture capital \\
\hline
\end{tabular}

Source: Compiled by researcher for this study.

China have three targets: end-users, advertisers and industries. According to traditional business concepts, marketing strategies include product, price, place and promotion (4Ps). Due to the fact that digital content products have significant uniqueness from other media products, the product strategy is therefore isolated.

Digital content products are characterised by 'media dualism'. This refers to the fact that media's 'clients' are not only advertisers, but also audiences. Media obtains high profits from advertisers when it attracts larger audiences. Digital content products also possess this feature that can acquire significant income from audiences or end users directly, for example, Wang
Film's revenue from box office. Some digital content companies such as Somode also provide a marketing channel for advertisers. These two kinds of marketing innovations are usually small-scale, continuous, interactive and customized.

The last marketing targets of Taiwanese digital content firms in China are industries, such as TV stations (Wang Film's CCTV strategy). This kind of B2B model is evident in off-line digital content industries, such as animation and art licensing. In order to conduct effective marketing, localization and guanxi are very important factors for transacting business in China.

China is a resource rich country; as such, some digital 
content companies employ resource acquisition strategies. The main resources that Taiwanese firms desire to obtain are labour and culturally symbolic materials.

As mentioned earlier, Wang Film has adopted two labour-related entrepreneurial strategies. The first is a partnership with Huqiu Technical Art School. Wang Film selects potential staff in Huqiu Technical Art School to provide one year in-school training and a half-year on-site training after the students graduate. When these students pass the one and a half-year trial period, they usually can become staff of Wang Film, formally. This strategy makes Wang Film's human resource system efficient. The second is the strategy of its animation satellite 'factories'. The 'factory' refers to small-scale animation studios that help Wang Film to produce some animation projects, in order to reduce fixed costs and exploit flexible human resources. Wang Film has become an intermediary in handling the entire production process between contracted animation firms and the animation 'factories'. Resource acquisition strategies have only been adopted in off-line digital content companies.

Another strategy only employed by web-based digital content companies is the organizational restructuring strategy. Organizational restructuring strategies occur when a company restructures its organization via management buyout or tries to change the market structure by introducing venture capital. Somode is an example of such strategies.

In China, capital is one of the major challenges for new ventures. Chinese commercial banks have more regulations than other countries. According to the Chinese Financial Yearbook (1989 to 1999), cited in Cooper and Yin (2006), only $0.03 \%$ of loans were granted to private companies by state-owned banks in 1998 .

\section{Conclusion}

This study emphasized on the way Taiwanese DC firms' entrepreneurial strategies were applied in the Chinese market. Wang Film used four entrepreneurial strategies in China. First, Suzhou Wang Film partnered with Huqiu Technical Art School; secondly, it set up a flexible employee system of 'animation satellite factories' to build an efficient and cost-effective entrepreneurial environment; thirdly, it built a long-term partnership with China Central Television (CCTV); fourthly, it launched a self-produced movie for cinemas, Fire Ball, led by Taipei Wang Film. The primary strategy of Somode is its e-magazine format. Somode's e-magazines converge all interactive materials, including voice, music, video and games to provide a rich media environment. The participation of users becomes a real thing, not just a 'slogan'. The users can read, listen or play Somode's e-magazines totally on demand. Another pre-eminent strategy of Somode is its advertising strategies, including strengthening new styles and the significance of e-magazines.

In this study, an attempt was made to integrate the 'Life
Cycle Model' with the dynamic concept of entrepreneurial strategies. Also, the significant differences in the evolution of entrepreneurial strategies between two types of digital content companies: off-line firms (Wang Film) and web-based firms (Somode) were outlined. Off-line digital content firms tended to adopt cost-reduction strategies in their initial stages and innovation strategies in subsequent stages. In contrast, web-based digital content companies mainly adopted innovation and quality-enhancement strategies, instead of cost-reduction strategies in whole.

\section{ACKNOWLEDGEMENTS}

The author is grateful to his supervisors of his Ph.D. thesis: Michael Keane and Terry Flew, who guided and encouraged him with insightful comments. He also warmly acknowledges the assistance of the Creative Industries Faculty, Queensland University of Technology (QUT) and the sponsor of Postgraduate Research Write Up Scholarship by QUT. In addition, he is very indebted to his family who raised him in a freethinking and fully supportive environment.

\section{REFERENCES}

Beijing Youth Today (2005). Fire Ball: Beijing Children Art Theatre Limited Company Makes Children Film Popular. Retrieved 10 July 2007, http://www.flashempire.com/news/newsread.php?id=2339.

Cassia L, Fattore M, Paleari S (2006). Entrepreneurial Strategy: Emerging Businesses in Declining Industries. Massachusetts: Edward Elgar.

Chen SJ (2006). Interactive Magazines Suffer Embarrassed Circumstances. China Computer World, 17 April, A26.

Cooper AC, Yin X (2006). Entrepreneurship in Developing Countries. In Entrepreneurial Strategies, ed. Cooper AC, Alvarez SA, Carrera AA, Mesquita LF, Vassolo RS. Malden: Blackwell Publishing, pp. 73-94.

Dimitratos P, Plakoyiannaki E (2003). Theoretical Foundations of an International Entrepreneurial Culture. J. Int. Entrep.., 1(2): 187-215.

DoNews (2007). Muzine Music Magazine Signed a Contact with Somode. http://www.donews.com/content/200707/47d001c99ed8 4d779 7243875382d049d.shtm

Galbraith C, Schendel D (1983). An Empirical Analysis of Strategy Types. Strateg. Manage. J., 4(2): 153-173.

Hisrich RD, Peters MP, Shepherd DA (2005). Entrepreneurship. New York: McGraw-Hill.

Hitt MA, Ireland RD, Camp SM, Sexton DL (2002). Strategic Entrepreneurship: Integrating Entrepreneurial and Strategic Management Perspectives. In Hitt MA, Ireland RD, Camp SM, and Sexton DL (ed.). Strategic Entrepreneurship. Malden: Blackwell Publishing.

Hui KL, Chau YK (2002). Classifying Digital Products. Commun. ACM. 45(6): 73-80.

Knight G (2000). Entrepreneurship and Marketing Strategy: The SME under Globalisation. J. Int. Mark., 8(2): 12-32.

Linn G (1996). China's Agribusiness Poses Problems for Western Firms. J. Commer. Commercial. 410(28854): 7.

Liu SH (2006). The Experience of 'Me, Love Beauty'. Youth J., 13:17.

Ma K (2006). E-magazines Start to Boom, and Its Value Chain Becomes Mature Gradually. Shenzhen Science and Technology Entrep. Monthly. 4: 30-32.

McKnight LW, Vaaler PM, Katz RL (2001). Introduction to Creative Destruction, In Creative Destruction: Business Strategies, in McKnight LW, Vaaler PM, Katz RL (ed.), Global Internet Economy. Cambridge: MIT Press. 
Miller D (1983). The Correlates of Entrepreneurship in Three Types of Firms. Manage. Sci., 29(7): 70-791.

Miller D (1988). Relating Porter's Business Strategies to Environment and Structure: Analysis and Performance Implications. Acad. Manage. J. 31(2): 280-308.

Ministry of Economic Affairs Digital Content Industry Office (2004). 2004 Digital Content Industry in Taiwan. Taipei: Ministry of Economic Affairs.

Mu Y (2005). Chinese Animation Movie 'Fire Ball' Held Preview in Beijing. Chinese Culture Newspaper, 5 Aug.

Orpen C (1985). The effects of Long-Range Planning on Small Business Performance: A Further Examination. J. Small. Bus. Manage., 1: 16-23.

Ozawa T, Castello S, Phillips RJ (2001). The Internet Revolution, the 'McLuhan' Stage of Catch-up, and Institutional Reforms in Asia. J. Econ., 34(2): 289-297.

Porter ME (1990). The Competitive Advantage of Nations. New York: The Free Press.

Quah D (2003). Digital Goods and New Economy: New Economy Handbook. USA: Elsevier Science.

Quintas P (2002). Implications of the Division of Knowledge for Innovation in Networks, in Mothe JDL, Link AN (ed.). Networks, Alliances and Partnerships in the Innovation Process. Massachusetts: Kluwer Academic Publishers.

Rexrodt G (1994). Germany companies notice the success of Taiwanese investors in China. United Daily, April 4.

Saxenian A (2006). The New Argonauts: Regional Advantage in a Global Economy. London: Harvard University Press.

Schuler RS, Jackson SE (1987). Linking Competitive Strategies with Human Resource Management Practices. Acad. Manage. Exec., 1(3): 207-219.
Shane S (2003). A General Theory of Entrepreneurship: the IndividualOpportunity Nexus. Cheltenham: Edward Elgar.

Small and Medium Enterprise Administration, Ministry of Economic Affairs (2006). White Paper on Small and Medium Enterprises in Taiwan. Taipei: Small and Medium Enterprise Administration, Ministry of Economic Affairs.

Sohu.Com (2007). Somode Yiwei Cheng: JV has Optimistic View with Content Platform, and E-magazines have Bright Future. Retrieved 5 September, http://it.sohu.com/20070802/n251381568.shtml

Straubhaar JD (1991). Beyond Media Imperialism: Asymmetrical Interdependence and Cultural Proximity. Crit. Stud. Mass Commun., 8: 39-59.

Tapscott D (1997). Strategy in the new economy. Strateg Leadersh., 25(6): 8-14.

Vorhies DW, Harker M, Rao CP (1999). The Capabilities and Performance Advantage of Market-driven Firms, Eur. J. Mark., 33: 1171-1202.

Wang X, Ralston DA (2000). Strategies for Small and Medium-sized U.S. Businesses Investing in China: Lessons from Taiwanese Companies. Thunderbird Int. Bus. Rev., 42(6): 677.

Zahra SA, George G (2002). International Entrepreneurship: The Current Status of the Field and Future Research Agenda, in Hitt MA, Ireland RD, Camp SM, Sexton DL (ed.), Strategic Entrepreneurship. Malden: Blackwell Publishing. 